\title{
Evaluation of the Assessment Program for Public School Teachers Performance Using Context, Input, Process, and Product (CIPP) Models
}

\author{
Nina Nurmasari*, Didik Notosudjono, Widodo Sunaryo \\ Postgraduate Program, Pakuan University Bogor, Indonesia
}

*Corresponding Author: Nina Nurmasari, Postgraduate Program, Pakuan University Bogor, Indonesia

\begin{abstract}
This research was carried out to improve the performance of teachers of Civil Servants in Bogor, West Java, Indonesia through evaluating the performance assessment program teachers who have been running since 2013. This research includes the type of program evaluation research with the CIPP model (context, input, process, and product) developed by Daniel Leroy Stufflebeam, using a descriptive qualitative approach. The data collection instruments used are interview guidelines, observation, and document study guidelines. Data analysis is done through data display, data reduction, conclusion, and data verification.

The results of this study indicate that the implementation of the teacher performance assessment program in terms of components of the context with aspects of needs analysis, policy foundation, goals, objectives and from the input side with aspects of resources, organization, procedures in the category of "good", but from the process side with time aspects, preparation, implementation, provision of values, reporting, monitoring / evaluation and from the side of product components with aspects of output and outcomes in the category of "satisfactory". The teacher job assessment program can be continued with improvements to process components and products.
\end{abstract}

Keywords: Program evaluation, CIPP model, Teacher Performance Evaluation, Job Evaluation

\section{INTRODUCTION}

According to Zeiner (2017), teachers are professional educators who have duties, functions, and essential roles in educating the life of the nation. Professional teachers in the assessment of work can participate in national development to realize Indonesian people who are cautious, excel in science and technology, have an aesthetic, ethical, noble character, and personality. In the current era of globalization, it is no exaggeration to say that the future of society, nation, and state, is mostly determined by the teacher.

To build the teaching profession as an honorable profession in achieving the vision of national education through a quality learning process, it is necessary to implement a teacher performance assessment program (teacher work assessment) on an ongoing and regular basis. As mandated by government regulation No. 16 of 2009, the teaching profession needs to be developed continuously and proportionally according to the teacher's functional position. Besides, so that the functions and tasks inherent in the teacher's operative position are carried out following the applicable rules, it is necessary to assess the teacher's performance (teacher's work assessment) which guarantees a quality learning process at all levels of education (Datnow,2015).

To see more clearly the evaluation of teacher work assessment programs in Bogor district, a preliminary survey was conducted through filling out questionnaires on 30 (thirty) respondents consisting of school supervisors, principals, appraisal teachers and teachers who were assessed within the Bogor district education office. Reference to the questions in the questionnaire is Government Regulation No. 35 of 2010 concerning technical instructions for implementing teacher operative positions and credit numbers.

Based on the background of the problem and the focus of the research above, the problem formulation in the evaluation of teacher performance appraisal programs is:

- How is the analysis of the needs, policies, goals, and objectives of the teacher performance appraisal program in the Bogor district education office? 
- What are the resource factors such as the provisions regarding appraisal conditions, supervisors, teacher performance profiles, facilities used in the implementation of teacher work assessments, organization and program procedures in the form of guidelines and assessment instruments used in the Bogor district education office?

- How the process of implementing the program, namely the implementation of teacher work assessment programs in the Bogor district education office includes the implementation time, preparation in which the teacher assessor and teacher assessed must understand the guidelines for implementing teacher work assessments, implementation where the assessor observes and monitors the learning process, giving value, reporting and monitoring / evaluating the method of performing the teacher's work assessment in its entirety?

- How are the outputs and outcomes of the teacher performance appraisal program in the Bogor district education office and the follow-up program of the results achieved?

\section{LITERATURE REVIEW}

The definition of program evaluation is delivered Rosi (2018), namely program evaluation is an investigation or data collection activity that produces information about the values contained in a program. Program evaluation becomes a process of events that involve systemic research, evaluating benefits, costs or interests, and as an effort to obtain information for decision-makers. The evaluation model has evolved to date, where the model was developed, developed and used in program evaluation. Jacob (2017) says there are six categories of program evaluation models developed by experts who focus on decision making, program elements, types of program activities, program implementation processes, achievement of program objectives, and program outcomes and influences. Creswell (2017) divides four types of evaluation models, namely, good oriented, decision-oriented, activity oriented and transactional oriented, and oriented control of program impact (research oriented).

Evaluation model CIPP According to Stufflebeam (2017), is a decision-oriented evaluation approach structured to help administrators make decisions. He formulated this evaluation as a process that describes, obtains and provides information that is useful for assessing choices. Whereas according to Aziz (2014). Which developing CIPP models in 1966 at Ohio State University, defines the evaluation model $C I P P$ as a process describe clear and specific information, where the data can be used as consideration in decision making. CIPP Evaluation model is through four stages, namely, context evaluation which is an evaluation of the extent to which the formulation of the goals and objectives of the program is by the needs of the organization or interested parties. The input evaluation is an evaluation of the extent of action plans, strategies, and the procedures of the program, as well as the infrastructure and resources concerned, can support the achievement of the desired goals or objectives in the context. Process evaluation is an assessment of how the program is implemented or implemented. Finally, product evaluation is an evaluation of the results, impacts, and outcomes of the implementation of the program.

Program evaluation of the teacher performance assessment that will be carried out is an evaluation to see the achievement of program objectives through the program implementation process. The CIPP evaluation model was chosen because this model is a system, carried out in stages, thoroughly in a management process and oriented to decision makers, so it is very suitable to be used in evaluating teacher's job assessment programs. With the CIPP evaluation model, complete data and information about the teacher's job assessment program can be obtained as a basis for decision making to be recommended to policymakers of the program. In addition, the evaluation model was CIPP chosen with the consideration that the CIPP evaluation model is a comprehensive evaluation model, in which in this model not only observes the results side but also analyzes the program from the components of context, input, process, and product which are seen as a complete set of elements.

The use of the CIPP models on the evaluation of job assessment programs the teacher will look at the program evaluation from the components:

- Context evaluation, to see the need assessment conducted on the program to be carried out following the goals, objectives, and policies of the teacher's job assessment program. Besides, an evaluation is also carried out on whether the formulation of objectives has been specific and 
achievable, whether it is on target and whether policies are carried out based on the needs of students, teachers, schools, and the government.

- Input evaluation is to evaluate the readiness of the resources possessed in implementing the program, program organization, and program procedures which together will achieve the expected goals. From the current input, it can be seen whether the teacher job assessment program planning has led to an effective, efficient, objective, and accountable process to describe the teacher's real performance in carrying out his duties.

- Process evaluation observes program implementation from the preparation stage which includes understanding the teacher's job assessment instrument and the validity of the teacher's job assessment team. Also, it examines the application which provides observations inside and outside the classroom, monitoring, and study of the teacher assessed, supervision carried out by the supervisor, reporting to the education office, analyzing the results and follow-up of the teacher's job assessment program. Process evaluation is expected to be able to answer whether the implementation of teacher's job assessment and teacher's job assessment implementing role has been effective, efficient, objective, fair, accountable, and able to identify problems in the implementation of teacher's job assessment.

\section{METHODS}

This study is an evaluation research (Evaluation Research) program with a descriptive qualitative approach. The technique used in this study is the program evaluation method with the CIPP (Context, Input, Process, Product) model developed by Stufflebeam which consists of formative evaluation and summative evaluation. The formative assessment includes components of context, input, and process while summative assessment includes product components. This model CIPP will examine in depth and thoroughly the necessary elements of CIPP. The research sample was a total of 88 (eighty-eight) Public Middle Schools in Bogor Regency spread across 40 (forty) sub-districts divided into 5 (five) regions.

\section{RESUlts AND DisCUSSION}

Discussion of the context components of the implementation of the Civil Servant Civil Servants Teacher Performance Evaluation in Bogor Regency, West Java Province includes an analysis of the needs, policy foundation, goals, and objectives of the program.

Evaluation on the aspects of the policy base shows that the average rating category is "good," which means that most of the criteria in the basis of program policies are fulfilled, namely the program is rolled out following applicable rules in the context of teacher development and fulfills the legality requirements. Evaluation on the aspects of interest showed that the average category of judgment is "good," which means that most of the criteria in the program objectives are met that goal formulated to increase motivation and sustainability communication between Teachers. Evaluation on the target aspect shows that the average assessment category is "good," which means that most of the criteria in the program objectives are met, namely clear program objectives and following the types/groupings of teachers to ensure continuity of communication and fulfill the legality provisions. This notion strengthens previous research on the importance of evaluation (Triana \& Rajiani, 2019).

The discussion of the input components of the implementation of the public junior high school civil servants teacher assessment program in Bogor Regency, west java province covers the resources, organization and program procedures. The resource aspect of the teacher job assessment program for public middle school teachers in Bogor Regency means that the assessment category is "sufficient," meaning that the evaluation criteria in the program resources have been partially fulfilled that program resources are clearly defined for career development and rank in the framework of teacher development and planning. Determination of resources has considered the needs in the implementation of the program, consisting of assessors job assessment teachers, supervisors, teacher performance profiles and infrastructure facilities. The organizational aspect of the teacher's job assessment program for public middle school teachers in Bogor Regency means that the assessment category is "good", meaning that the evaluation criteria in the program organization have been fulfilled that the program organization is set in stages to ensure continuity of communication between the teacher and statutory legal provisions. Program organizations are determined based on their respective functions and roles, consisting of interrelated institutions, namely the ministry of education and culture, provincial education office, district/city education office, and schools. This finding 
Evaluation of the Assessment Program for Public School Teachers Performance Using Context, Input, Process, and Product (CIPP) Models

reinforces the previous research on the importance of implementation of assessment ( Ramie $\&$ Rajiani, 2019).

The procedure aspects of the teacher's job assessment program for public school teachers in Bogor Regency mean the assessment category is "good," saying that the evaluation criteria in program procedures have been primarily fulfilled that the system is determined by the principles of validity, reliability, and practicality by evaluating each main task activity. Teachers with the stages of preparation, implementation, reporting and monitoring/evaluation with teacher duties as stated Ministry Regulation No. 35 Of 2010 concerning technical guidelines for the implementation of teacher's working position and credit numbers.

Discussion component of the implementation process teacher performance appraisal of civil servants junior high school in Bogor Regency, West Java province includes time, preparation, implementation, scoring, reporting, and monitoring/evaluation.

The aspect of the implementation of the teacher's job assessment program for public middle school teachers in Bogor Regency means that the assessment category is "good," saying that the evaluation criteria in the implementation of the program are mostly fulfilled that the school carries out the teacher job assessment program periodically once a year. It is determined according to the need to obtain teacher performance data every year. The assessment period is once a year, with a span of six weeks at the end of the odd semester or six weeks at the end of even semester, before the active day of semester learning ends.

The preparation aspects of the teacher's job assessment program for public middle school teachers in Bogor Regency mean the assessment category is "sufficient," meaning that the evaluation criteria in program preparation have been partially fulfilled. The assessment team is not yet fully competent in carrying out their duties as teacher job assessment assessors, because some evaluators have not certified. The aspects of the implementation of the teacher's job assessment program for public middle school teachers in Bogor Regency mean that the assessment category is "sufficient," meaning that the evaluation criteria in the implementation of the program have been partially fulfilled. , but the discussion at the stage before the observation still revolves around administrative matters, namely the files that must be prepared by a teacher.

The reporting aspect of the teacher's job assessment program for public middle school teachers in Bogor Regency is that the assessment category is "sufficient," meaning that the evaluation criteria in implementing the program have been partially fulfilled. Reporting the results of each teacher's job assessment to the principal through the assessment team has not been done well with the report document evidence that is not available. The school has also not recapitulated and analyzed the results of the teacher's job assessment to see the teacher's performance profile in a given year.

The monitoring/evaluation aspect of the teacher's job assessment program for public middle school teachers in Bogor Regency means that the assessment category is "less," saying that the monitoring/evaluation criteria in the implementation of the program are only a small part fulfilled. Maximally. The supervisor's attendance to the school related to the teacher's job assessment program is limited to asking the teacher's job assessment results in general, and there is no specific monitoring and evaluation instrument regarding the teacher's job assessment program.

The output aspect the teacher's job assessment program for public middle school teachers in Bogor Regency means that the assessment category is "sufficient," saying that the criteria output in program implementation has been partially fulfilled. Teachers are beneficial to the organization in the form of a teacher's job assessment, teacher appreciation, and teacher career improvement. However, the recapitulation and analysis of the results of the teacher's job assessment have not been conducted by the school so that the profile of the teacher's performance as a whole is not yet known both in terms of the teacher's strengths or weaknesses. This makes the teacher's job assessment program not yet able to provide significant benefits for the organization. Because the analysis of teacher job assessment results has not been implemented, teachers cannot be identified with an excellent performance so that awards are only given verbally in the form of praise and opportunities for career advancement.

The aspects of outcome the teacher job assessment program for public middle school teachers in Bogor Regency mean that the assessment category is "sufficient," saying that the criteria outcome in implementing the program have been partially fulfilled. The school should ensure the teacher job 
Evaluation of the Assessment Program for Public School Teachers Performance Using Context, Input, Process, and Product (CIPP) Models

assessment program is beneficial for teachers to improve performance to improve education services. Improve the teacher's self-image, and improve the quality of education. However, the findings in the field indicate that schools have not been able to ensure that the teacher's job assessment program can improve performance. They can enhance education services because there are no results of the analysis that become the basis that the implementation of teacher job assessment that has been running for several years can significantly improve teacher performance.

Teacher job assessment results for some teachers can improve self-image in the form of selfconfidence, but for others, the effects of teacher's job assessment are seen administratively so that the benefits are more on developing the elements of learning administration. Teacher's job assessment program has not been ascertained to enhance the quality of education in general.

\section{CONCLUSION}

Teacher's job assessment is conducted to see the teacher's performance in carrying out his primary task, namely to carry out learning, mentoring and the implementation of other duties relevant to school functions. Teacher job assessment results are then used to help teachers improve their knowledge and skills in specific competencies as needed. Thus, teachers are expected to be able to contribute optimally to enhance the quality of learning of students and at the same time help teachers in developing their careers as professionals.

The implementation of the teacher job assessment program can be continued with improvements in aspects of resources, preparation, execution, reporting, monitoring/evaluation so that the aspects output and outcome are significantly improved. Aspects output and outcome cannot be corrected separately from other elements because output and outcome are the effects of what is done on other issues.

\section{REFERENCES}

[1] Aziz, Shamsa, Munazza Mahmood, and Zahra Rehman. "Implementation of CIPP Model for Quality Evaluation at School Level: A Case Study." Journal of Education and Educational Development 5, no. 1 (2018): 189-206.

[2] Creswell, John W., and Cheryl N. Poth. Qualitative inquiry and research design: Choosing among five approaches. Sage publications, 2017.

[3] Datnow, Amanda, and Lea Hubbard. "Teachers' Use of Assessment Data to Inform Instruction: Lessons from the Past and Prospects for the Future." Teachers College Record 117, no. 4 (2015).

[4] Garic, Gabrijela Grujic, and Maja Sokolovic Ignjacevic. "Innovated program for preschool teachers'education and self-assessment of their musical competences." TEME (2018): 899-916.

[5] Jacobs, Francine H. "The five-tiered approach to evaluation: Context and implementation." In Evaluating family programs, pp. 37-68. Routledge, 2017.

[6] Ramie, A. and Rajiani, I., 2019. ARCS Module (Attention, Relevance, Confidence, Satisfaction) to Increase Classroom Motivation for Pregnant Women at Public Health Center. Indian Journal of Public Health Research \& Development, 10(1), pp.401-405.

[7] Rossi, Peter H., Mark W. Lipsey, and Gary T. Henry. Evaluation: A systematic approach. Sage publications, 2018.

[8] Stufflebeam, Daniel L., and Guili Zhang. The CIPP evaluation model: How to evaluate for improvement and accountability. Guilford Publications, 2017.

[9] Triana, Neny, and Ismi Rajiani. "Interprofessional Education Module in Achieving Ethics/Values, Roles, Responsibilities, Professional Communication Competencies, and Team Collaboration among the College of Health Students." Indian Journal of Public Health Research \& Development 10, no. 1 (2019): 406-408.

[10] Zeichner, Kenneth M. "The Struggle for the Soul of Teaching and Teacher Education in the US." The Struggle for the Soul of Teacher Education, pp. 31-51. Routledge, 2017.

Citation: Nina Nurmasari, et.al. "Evaluation of the Assessment Program for Public School Teachers Performance Using Context, Input, Process, and Product (CIPP) Models" International Journal of Managerial Studies and Research (IJMSR), vol 7, no. 4, 2019, pp. 35-39. doi: http://dx.doi.org/10.20431/ 2349-0349.0704001.

Copyright: () 2019 Authors. This is an open-access article distributed under the terms of the Creative Commons Attribution License, which permits unrestricted use, distribution, and reproduction in any medium, provided the original author and source are credited. 